\title{
LATHE SELECTION USING ANALYTIC HIERARCHY PROCESS AND INFORMATION AXIOM
}

\author{
Aykut Kentli' ${ }^{1}$, Serhat Akbaş²
}

\begin{abstract}
Selection of appropriate equipment, place, or employee is a problem that needs consideration by industry, as capacities develop and efficiencies become more valued over the recent decades. Several decisionmaking techniques have been developed and applied to many different areas to evaluate their reliability. This study focuses on the application of a hybrid decision-making technique of Analytic Hierarchy Process and Information Axiom to solve the problem of lathe selection. Results show that appropriate machine tools can easily be selected within a short time using this approach.
\end{abstract}

UDC Classification: 621.7 DOI: http://dx.doi.org/10.12955/cbup.v4.864

Keywords: Analytic Hierarchy Process, Information Axiom, Lathe Selection.

\section{Introduction}

It is often difficult to select one option among many, especially with multiple selection criteria. Selecting the correct option becomes a problem for companies because the consequences of selection are directly related to profit. To ease the process, various techniques have been developed.

One of the oldest and simplest techniques is Analytic Hierarchy Process (AHP). Saaty (1980) developed this technique to solve complex decision problems. The main aim was to define and normalize the importance of criteria to form a single criterion for comparing alternatives. Later, different researchers proposed new techniques, such as TOPSIS, PROMETHEE, ELECTRE, and VIKOR.

As techniques were developed, they were applied to many different areas: education, engineering, government, industry, management, manufacturing, personal, political, social, and sports (Alias, Hashim, \& Samsudin, 2008). A machine selection problem is where one needs to choose an alternative with the best attributes considering the comparison criteria. Studies on machine selection problems are broadly classified into categories, such as product design, manufacturing process, flexible manufacturing system, machine tool, material handling system, and robotic (Kentli \& Uçak, 2011).

Yurdakul (2004) used the AHP technique to resolve the machine tool selection problem. He selected the best vertical machining center among five alternatives, considering the cost of items (material, labor, and factory overheads). Çimren, Budak, and Çatay (2004) designed software using the same technique to identify the best machining center among 236 alternatives, considering reliability, precision, and cost. Tsai, Cheng, Wang, and Kao (2010) selected the best 4-axis CNC machining center among three alternatives, considering reliability, cost, maintenance and service, safety and environment, and space.

Hybrid techniques have been developed to improve accuracy of applied techniques, for example, fuzzy AHP to handle uncertainty in extracting information from users or experts. Ayağ and Özdemir (2006) selected the best CNC vertical turning center among 19 alternatives. Önüt, Kara, and Efendigil (2008) used a hybrid fuzzy AHP and fuzzy TOPSIS technique and selected the best CNC machining center among four alternatives considering cost, operative flexibility, installation easiness, maintainability and serviceability, productivity, compatibility, safety, and user friendliness. Dura'n and Aguilo (2008) selected the best CNC turning center among three alternatives, considering flexibility, operation easiness, reliability, quality, implementation easiness, and maintainability. Moreover, Dağdeviren (2008) combined PROMETHEE with AHP and selected the best milling machine, considering price, weight, power, spindle, diameter, and stroke. Guan, Wang, \& Tao (2009) selected the best machining processes for a product, considering cost, quality, and operation time, using a hybrid technique of GA and AHP.

\footnotetext{
${ }^{1}$ Aykut Kentli, Marmara University, Istanbul, Turkey, akentli@marmara.edu.tr

2 Serhat Akbaş, Istanbul Technical University, Istanbul, Turkey, s_akbas89@hotmail.com
} 
The previously mentioned techniques calculate importance weights considering only expert opinion. This could lead to varying results because it relies on surveys or interviews from varying experts, who each have individual experience in the area. Thus, other information is needed in the system for more robust results. Therefore, an Information Axiom combined with the AHP has been used to accomplish this aim (Tarcan, 2005). A few applications of this combination are found in literature, for example, Kentli and Akbaş (2011) applied the technique to a machine selection problem. This study aims to apply the same approach to the problem of lathe selection.

\section{Hybrid Technique of AHP and Information Axiom}

The AHP ranks alternative solutions by prioritizing requirements with the pairwise comparison involving expert opinion to define the priorities. More specifically, the problem is systematically divided into data of interrelated elements, which are normalized prior to comparing and ranking the data. Having multiple criteria complicates the problem in that an alternative with low ranking in some criteria may inadvertently be selected as best choice. The AHP method involves six steps as shown in Figure 1 (see Annex).

The use of the Information Axiom of axiomatic design aims for information content calculated from numerical values of the products' properties. The product with the lowest information content is deemed the best. Unlike the AHP, the Information Axiom uses certain and constant values rather than values that change from person to person. However, the Information Axiom treats all criteria in the design problem with equal importance, which may not be the case. The Information Axiom is used to evaluate the weights of the criteria, and the comparison of alternatives is then performed using AHP.

For a given design, the information content can be obtained for different applications, according to Kar (2000), as follows:

$$
\begin{aligned}
& I N=C\left[\left(m_{s}-m_{d}\right)^{2}+\sigma_{s}^{2}\right] \\
& I S=C\left[m_{s}^{2}+\sigma_{s}^{2}\right] \\
& I L=C\left[\left(m_{s}-m_{d}\right)^{2}+\sigma_{s}^{2}\right]^{-1}
\end{aligned}
$$

where "IN" is the information content for nominal-the-best design, "IS" for smaller-the-better design, and "IL" for larger-the-better; while " $\mathrm{C}$ " is a proportional constant that depends on the design specifications, " $\mathrm{m}_{\mathrm{s}}$ " the mean of the system range, " $\mathrm{m}_{\mathrm{d}}$ " the mean of the design range, and " $\sigma_{\mathrm{s}}$ " the variation of the system range.

\section{Selecting Best Lathe}

As the case study, a lathe selection problem was chosen. Data found in literature were used in the study to compare results of lathes (Athawale \& Chakraborty, 2010). The capital cost was important, as starting the process with less expenditure provides an opportunity to produce the same product at a lower price. Also, having a CNC lathe capable of different products allows for greater gain in a competitive market. Thus, several different tools (for tool capacity, maximum machining diameter, and maximum machining length) and rapid processing (for spindle speed range, rapid traverse rate of $\mathrm{X}$, and Z-axis) were used as comparison criteria. Data used in the study are shown in Table 1 and the comparison matrix in Table 2 (see Annex).

\section{Results}

Table 3 (see Annex) shows the comparison of the lathes. Ranking of seven selected CNC lathes are shown from seven criteria perspectives. As a result, VTURN 16 was chosen as the best candidate. The least-preferred choice was EX-106. Possibly, the rapid traverse rate values were ineffective in the selection, as the best had the minimum and the least-preferred had the maximum value.

\section{Conclusion}

A hybrid methodology (AHP with Information Axiom) was successfully applied to a lathe selection problem. The study showed that this methodology can be applied for robust results. The results 
indicate that VTURN 16 lathe was the best choice, though consideration of different criteria (e.g., maintenance cost and weight) could alter this outcome. Comparison with literature showed similar results to those obtained in this study.

\section{Acknowledgments}

This was supported by Marmara University Scientific Research Projects Committee (BAPKO).

\section{References}

Alias, M. A., Hashim, S. Z. M., \& Samsudin, S. (2008). Multi criteria decision making and its applications: a literature review. Jurnal Teknologi Maklumat, 20(2),129-152.

Athawale, V. M., \& Chakraborty, S. (2010). A TOPSIS method-based approach to machine tool selection, presented at International Conference on Industrial Engineering and Operations Management, Dhaka, Bangladesh, 2010.

Aya $\breve{g}$ Z., \& Özdemir, R. G. (2006). A fuzzy AHP approach to evaluating machine tool alternatives. Journal of Intelligent Manufacturing, 17, 179-190. doi: 10.1007/s10845-005-6635-1

Çimren, E., Budak, E., \& Çatay, B. (2004). Development of a machine tool selection systems using analytic hierarchy process, presented at 4th CIRP International Seminar on Intelligent Computation in Manufacturing Engineering, Sorrento, Italy, 2004.

Dağdeviren, M. (2008). Decision making in equipment selection: an integrated approach with AHP and PROMETHEE. Journal of Intelligent Manufacturing, 19, 397-406. doi: 10.1007/s10845-008-0091-7

Dura'n, O., \& Aguilo, J. (2008). Computer-aided machine-tool selection based on a Fuzzy-AHP approach. Expert Systems with Applications, 34, 1787-1794. doi: 10.1016/j.eswa.2007.01.046

Guan, X., Wang, Y., \& Tao, L. (2009). Machining scheme selection of digital manufacturing based on genetic algorithm and AHP. Journal of Intelligent Manufacturing, 20, 661-669. doi: 10.1007/s10845-008-0155-8

Kar, A. K. (2000). Linking Axiomatic Design and Taguchi Methods via Information Content in Design, presented at First International Conference on Axiomatic Design, Cambridge, USA, 2000.

Kentli, A., \& Ucak, G. (2011). AHP Applications on Machine Selection Problems, presented at 1st International Symposium and 10th Balkan Conference on Operational Research, Thessaloniki, Greece, 2011.

Kentli, A., \& Akbaş, S. (2011). Machine Tool Selection Based on AHP Integrated with Information Axiom, presented at 1st International Symposium and 10th Balkan Conference on Operational Research, Thessaloniki, Greece, 2011.

Önüt, S., Kara, S. S., \& Efendigil, T. (2008). A hybrid fuzzy MCDM approach to machine tool selection. Journal of Intelligent Manufacturing, 19, 443-453. doi: 10.1007/s10845-008-0095-3

Saaty, T. L. (1980). The Analytic Hierarchy Process: Planning, Priority Setting, Resource Allocation. New York: McGrawHill.

Tarcan, E. (2005). Evaluation of sub-component alternatives in a product design (MSc Thesis). Retrieved from https://tez.yok.gov.tr/UlusalTezMerkezi/TezGoster?key=7d53ed97e31a8bd353d20ca3991cc9a57174c8b5f621bc8c5dcdc938 3c6eb3f68a307ca8ed57d73b.

Tsai, J. P., Cheng, H. Y., Wang, S. Y., \& Kao, Y. C. (2010). Multi-Criteria Decision Making Method for Selection of Machine Tool, presented at IEEE international symposium on computer communication control and automation (3CA), Tainan, China, 2010. doi: 10.1109/3CA.2010.5533376

Yurdakul, M. (2004). AHP as strategic decision making tool to justify machine tool selection. Journal of Materials Processing Technology, 146, 365-376. doi: 10.1016/j.jmatprotec.2003.11.026 


\section{Annex}

Figure 1: Schematic representation of the hybrid approach

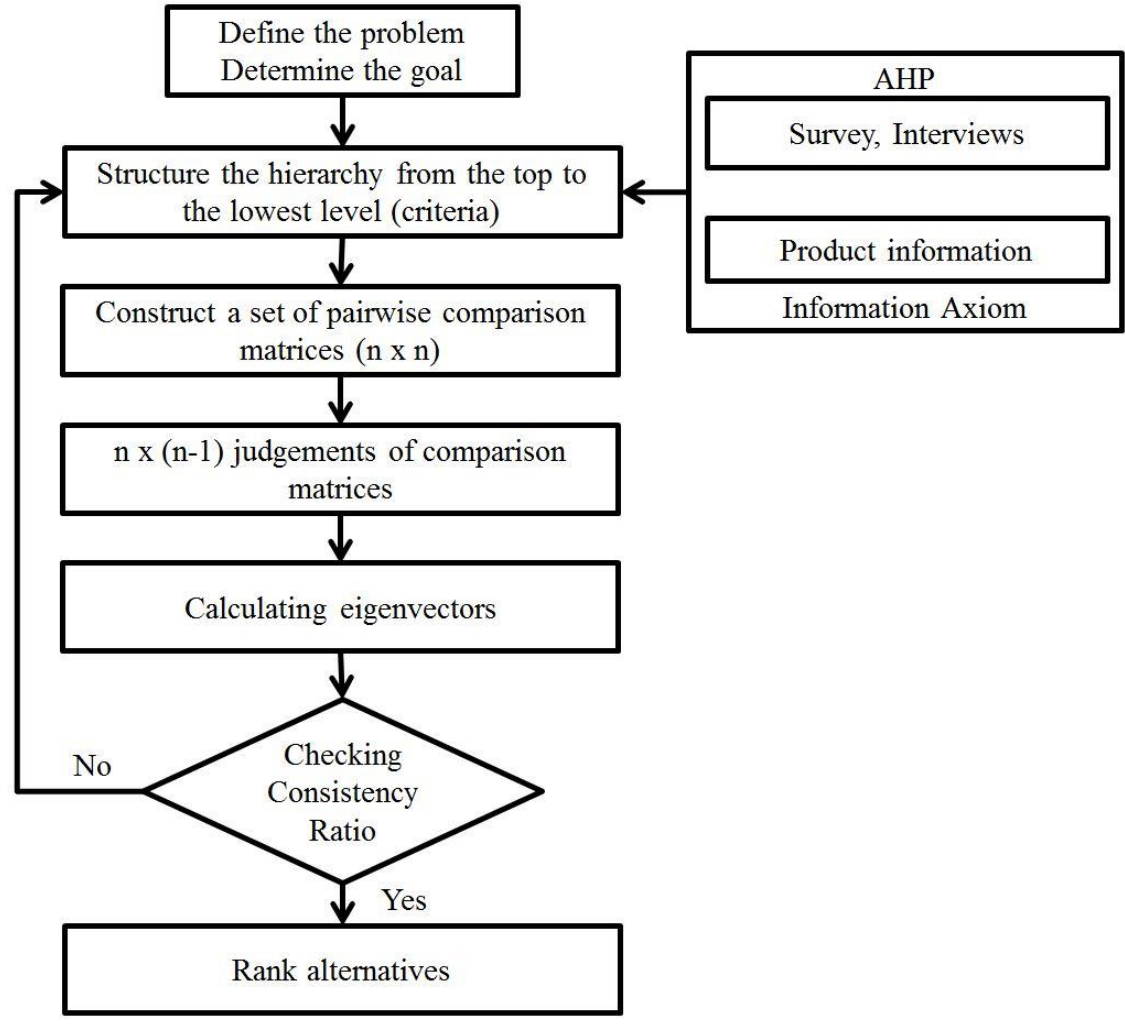

Source: Authors

Table 1: Data of lathes

\begin{tabular}{|l|c|r|r|r|r|r|r|}
\hline \multicolumn{1}{|c|}{ Lathes } & $\begin{array}{c}\text { CC } \\
\text { (Capital } \\
\text { Cost) } \\
\text { million } \\
\text { USD }\end{array}$ & $\begin{array}{c}\text { SS } \\
\text { (Spindle } \\
\text { Speed } \\
\text { Range) }\end{array}$ & $\begin{array}{c}\text { TC } \\
\text { (Tool } \\
\text { Capacity) }\end{array}$ & $\begin{array}{c}\text { TX } \\
\text { Trapid } \\
\text { Traverse } \\
\text { Rate of } \\
\text { X-Axis) }\end{array}$ & $\begin{array}{c}\text { TZ } \\
\text { (Rapid } \\
\text { Traverse } \\
\text { Rate of } \\
\text { Z-Axis) }\end{array}$ & $\begin{array}{c}\text { MD } \\
\text { (Max. } \\
\text { Machining } \\
\text { Dia.) }\end{array}$ & $\begin{array}{c}\text { ML } \\
\text { Machining } \\
\text { Length) }\end{array}$ \\
\hline $\begin{array}{l}\text { YANG } \\
\text { ML-5A }\end{array}$ & 1.20 & 5590 & 8 & 24 & 24 & 205 & 350 \\
\hline EX-106 & 1.32 & 4950 & 12 & 24 & 30 & 240 & 340 \\
\hline $\begin{array}{l}\text { VTURN } \\
\text { 16 }\end{array}$ & 1.10 & 5940 & 12 & 12 & 15 & 230 & 600 \\
\hline $\begin{array}{l}\text { FEMCO } \\
\text { HL-15 }\end{array}$ & 1.20 & 5940 & 12 & 12 & 16 & 150 & 330 \\
\hline $\begin{array}{l}\text { ECOCA } \\
\text { SJ20 }\end{array}$ & 1.18 & 3950 & 8 & 24 & 24 & 250 & 330 \\
\hline $\begin{array}{l}\text { TOPPER } \\
\text { TNL-85A }\end{array}$ & 1.20 & 3465 & 8 & 20 & 24 & 264 & 400 \\
\hline $\begin{array}{l}\text { ATECH } \\
\text { MT-52S }\end{array}$ & 1.38 & 4752 & 12 & 20 & 245 & 350 \\
\hline
\end{tabular}

Source: Authors 
Table 2: Pair-wise comparison matrix of lathe criteria

\begin{tabular}{|l|r|r|r|r|r|c|c|r|}
\hline Criteria & CC & SS & TC & TX & TZ & MD & ML & Priority Vector \\
\hline CC & 1 & 1 & 1 & $1 / 2$ & 1 & $1 / 2$ & 1 & 0.1143 \\
\hline SS & 1 & 1 & 1 & 1 & 1 & 3 & 2 & 0.1815 \\
\hline TC & 1 & 1 & 1 & 1 & 2 & 2 & 2 & 0.1793 \\
\hline TX & 2 & 1 & 1 & 1 & $1 / 2$ & $1 / 3$ & 1 & 0.1273 \\
\hline TZ & 1 & 1 & $1 / 2$ & 2 & 1 & $1 / 2$ & $1 / 2$ & 0.1154 \\
\hline MD & 2 & $1 / 3$ & $1 / 2$ & 3 & 2 & 1 & 1 & 0.1620 \\
\hline ML & 1 & $1 / 2$ & $1 / 2$ & 1 & 2 & 1 & 1 & 0.1202 \\
\hline
\end{tabular}

Source: Authors

Table 3: Ranking matrix

\begin{tabular}{|l|c|c|c|c|c|c|c|c|}
\hline Lathe models & CC & SS & TC & TX & TZ & MD & ML & $\boldsymbol{\Sigma}$ \\
\hline YANG ML-5A & 0.0177 & 0.0245 & 0.0029 & 0.0257 & 0.0183 & 0.0085 & 0.0087 & 0.1064 \\
\hline EX-106 & 0.0076 & 0.0235 & 0.0419 & 0.0409 & 0.0559 & 0.0321 & 0.0101 & 0.2117 \\
\hline VTURN 16 & $\underline{0.0499}$ & $\underline{0.0420}$ & $\underline{0.0414}$ & $\underline{0.0039}$ & $\underline{0.0039}$ & $\underline{0.0253}$ & $\underline{0.0930}$ & $\underline{0.2595}$ \\
\hline FEMCO HL-15 & 0.0197 & 0.0299 & 0.0294 & 0.0028 & 0.0038 & 0.0024 & 0.0051 & 0.0931 \\
\hline ECOCA SJ20 & 0.0224 & 0.0078 & 0.0030 & 0.0260 & 0.0185 & 0.0238 & 0.0047 & 0.1061 \\
\hline TOPPER TNL-85A & 0.0251 & 0.0031 & 0.0041 & 0.0227 & 0.0260 & 0.0361 & 0.0314 & 0.1486 \\
\hline ATECH MT-52S & 0.0025 & 0.0122 & 0.0277 & 0.0169 & 0.0193 & 0.0191 & 0.0091 & 0.1068 \\
\hline
\end{tabular}

Source: Authors 